\title{
A Novel Mosfet Single Switch Resonant Power Converter For Reducing Switching Loss And Increase Energy Conversion
}

\author{
1. K.KIRANMAI, 2. P.OBULESU, Assistant Professor \\ 1, 2. Department of EEE, Dr.K.V.Subba Reddy College of Engineering For Women \\ 1.kkiranmai11@gmail.com, 2.puli.obulesu@gmail.com
}

\begin{abstract}
This paper develops a novel single-switch resonant power converter for renewable energy generation applications. This circuit topology integrates a novel single-switch resonant inverter with zero-voltage switching (ZVS) with an energyblocking diode with zero-current switching (ZCS). The energy-blocking diode with a direct-current output filter filters the output stage of the novel single-switch resonant inverter. Only one active power switch is used for power energy conversion to reduce the cost of active power switches and control circuits. The active power switch is controlled by pulse width modulation at a fixed switching frequency and a constant duty cycle. When the resonant converter is operated at discontinuous conduction mode, the inductor current through the resonant tank could achieve ZCS of the energy-blocking diode. Accordingly, a high energy conversion efficiency is ensured. Operating principles are derived, and analyses are carried out based on the equivalent circuits for the proposed power converter under different operating modes. The operating principles of the converter were verified using a 32.4-W $70-\mathrm{kHz}$ experimental photovoltaic-powered load system. Given appropriately chosen circuit parameters, the active power switch can be operated with ZVS, and a measured energy conversion efficiency of the proposed topology of $97.3 \%$ can be achieved. Experimental results demonstrate a satisfactory performance of the proposed topology, which is particularly suited to the energy conversion applications in renewable energy generation systems.
\end{abstract}

\section{INTRODUCTION}

Nowadays, most power that is used to meet our daily needs is obtained from fossil fuels. Owing to increases in consumption, fossil fuel sources may be exhausted in the near future. The Kyoto agreement on the global reduction of greenhouse gas emissions that are produced by the burning of fossil fuels seeks a reduction in the use energy from such sources. However, Taiwan is a highly energy-dependent nation, which meets approximately $97 \%$ of its energy needs by importing fuels. Environmental pollution and greenhouse gas emissions are becoming significant environmental issues in the country. Therefore, renewable energy has become attractive in recent years, following the implementation of a policy for sustainable development and mitigation of environmental pollution in Taiwan. Accordingly, means of generating renewable energy are being developed. They include wind turbines, photovoltaic (PV) modules, and fuel cell systems. PV power generation systems have been regarded as the most promising future sources of energy because of their advantages, such as the absence of a need for fuel and the associated cost saving, low maintenance, and lack of noise. Fortunately, Taiwan is located in a subtropical zone that is close to the equator, and southern Taiwan, in particular, experiences strong sunshine in the sum-mer. Consequently, the energy collected on PV arrays is utilized as the source of a renewable energy for reduction of fossil fuel energy.

Basic circuit:

The circuit and operating principles of the novel singleswitch resonant power converter. Chapter 5 introduces its operating characteristics. Chapter 6 discusses its implementation and test results. Chapter 7 draws conclusions.

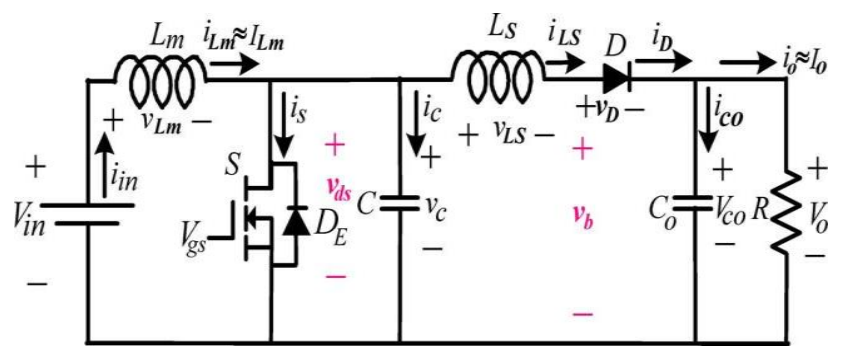

Fig. 1. Basic circuit diagram of the proposed novel single-switch resonant power converter

\section{BASIC SWITCHING}

\section{I.A.CHOPPER CIRCUITS}

Many industrial applications require power from DC sources. Several of these applications, however, perform better in case these are fed from variable DC voltage sources. Examples of such DC system are subway cars, trolley buses, battery-operated vehicles, battery charging etc.

\section{(1) AC Link Chopper :}

In the ac link chopper dc is first converted to ac by an inverter ( $\mathrm{dc}$ to ac converter). AC is then stepped-up or stepped-down by a transformer which is then converted back to a dc by a diode rectifier. As the conversion is in two stages, dc to ac and then ac to dc, the link chopper is costly, bulky and less efficiency 


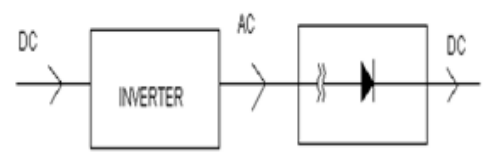

Fig I.1(a) AC link chopper
Fig I.2(b) DC chopper

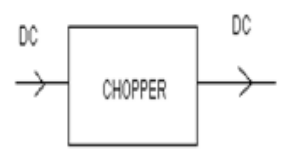

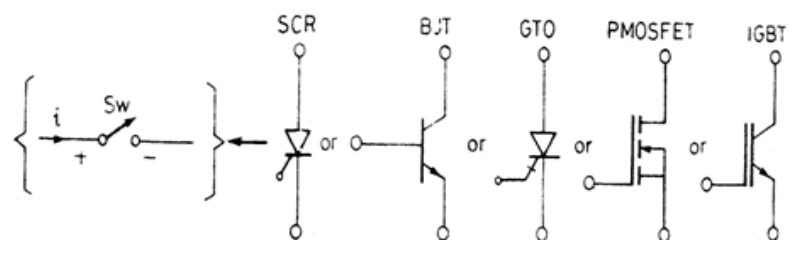

Fig I .3(c) Represented of power semiconductor device

\section{(2)DC Chopper :}

A chopper is a static device that converts fixed dc input voltage to a variable dc output voltage directly. A chopper may be thought of as dc equivalent of an ac transformer since they behave in an identical manner. As choppers involve one stage conversion, these are more efficient.

\section{I.B.BOOST CONVERTER}

A boost converter (step-up converter) is a power converter with an output DC voltage greater than its input DC voltage.

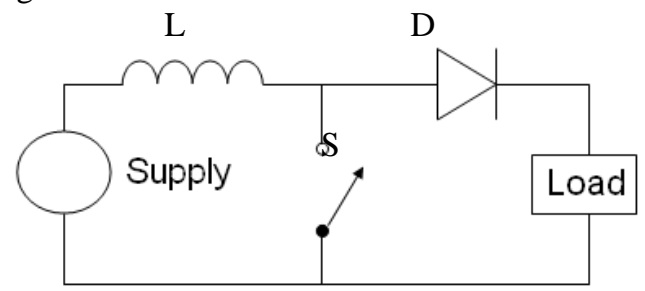

Fig I.4 Basic schematic of a boost converter, The switch is typically a MOSFET, IGBT or BJT.

\section{ZVS AND ZCS RESONANT CONVERTERS 1.ZERO CURRENT SWITCHING RESONANT CONVERTERS}

The switches of Zero Current Switching (ZCS) resonant converters turn on and off at zero current. The resonant circuit that consists $\mathrm{f}$ switch $\mathrm{S}_{1}$, inductor $\mathrm{L}$, and capacitor $\mathrm{C}$ is shown. The inductor $\mathrm{L}$ is connected in series with power switch $S_{1}$ to achieve ZCS. It is classified into two types - L type and $M$ type.

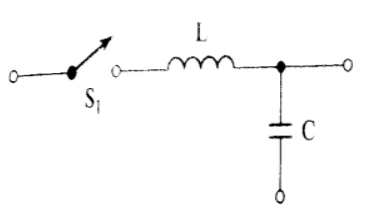

L-type

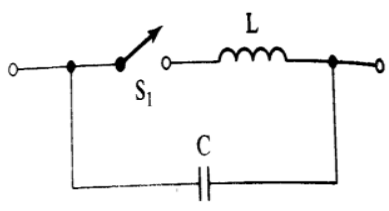

(a) Switch types
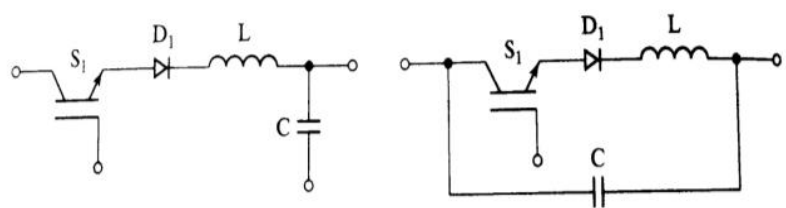

(b) half-wave types

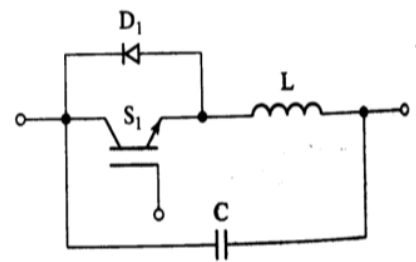

(c) Full-wave types

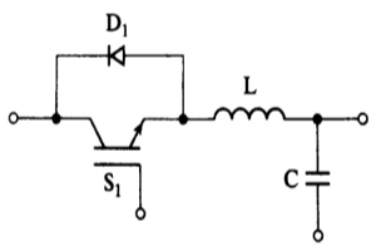

The circuit operation can be divided into 5 modes whose equivalent circuits are shown. We shall redefine the time origin, $\mathrm{t}=0$, at the beginning of each mode.

Mode 1 - This mode is valid for $0 \leq t \leq t_{1}$. Switch $S_{1}$ is turned on and diode $\mathrm{D}_{\mathrm{m}}$ conducts. The inductor current iL which rises linearly is given by

$$
\mathrm{I} \mathrm{L}=\left(\mathrm{V}_{\mathrm{S}} / \mathrm{L}\right) \mathrm{t}
$$

This mode ends at time $\mathrm{t}=\mathrm{t} 1$ when $\mathrm{iL}_{\mathrm{L}}\left(\mathrm{t}=\mathrm{t}_{\mathrm{l}}\right)=\mathrm{I}_{0}$.

That is $\mathrm{t}_{1}=\mathrm{I}_{0} \mathrm{~L} / \mathrm{V}_{\mathrm{S}}$,

Mode 2 - This mode is valid for $0 \leq t \leq t_{2}$. Switch $S_{1}$ remains on but diode Dm is off. The inductor current $i_{L}$ is given by

$$
\begin{aligned}
& \mathrm{IL}_{\mathrm{L}}=\mathrm{Im}_{\mathrm{m}} \sin \omega_{\mathrm{O}} \mathrm{t}+\mathrm{I}_{0} \\
& \text { where } I_{m}=V_{s} \sqrt{\frac{C}{L}} \text { and } \omega_{0}=\frac{1}{\sqrt{L C}}
\end{aligned}
$$

The capacitor voltage $v_{c}$ is given by $v_{c}=V_{S}(1-\cos \omega 0 t)$ The peak current which occurs at $t=\frac{\pi}{2} \sqrt{\mathrm{LC}}$ is

$$
\mathrm{I}_{\mathrm{p}}=\mathrm{Im}_{\mathrm{m}}+\mathrm{I}_{0}
$$

The peak capacitor voltage is given by

$$
\mathrm{V} \mathrm{c}(\mathrm{pk})=2 \mathrm{~V}_{\mathrm{S}}
$$

This mode ends at $\mathrm{t}=\mathrm{t}_{2}$ when $\mathrm{iL}_{\mathrm{L}}\left(\mathrm{t}=\mathrm{t}_{2}\right)=\mathrm{I}_{0}$ and $\mathrm{v}_{\mathrm{c}_{(\mathrm{pk})}}\left(\mathrm{t}=\mathrm{t}_{2}\right)=2 \mathrm{~V}_{\mathrm{c}}=2 \mathrm{~V}_{\mathrm{s}}$.

Therefore $\mathrm{t}_{2}=\pi \sqrt{\mathrm{LC}}$

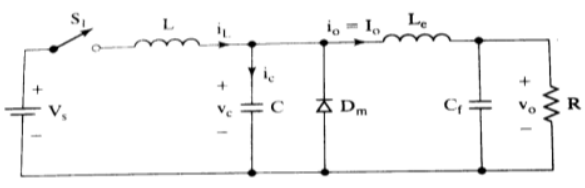

(a) Circuit
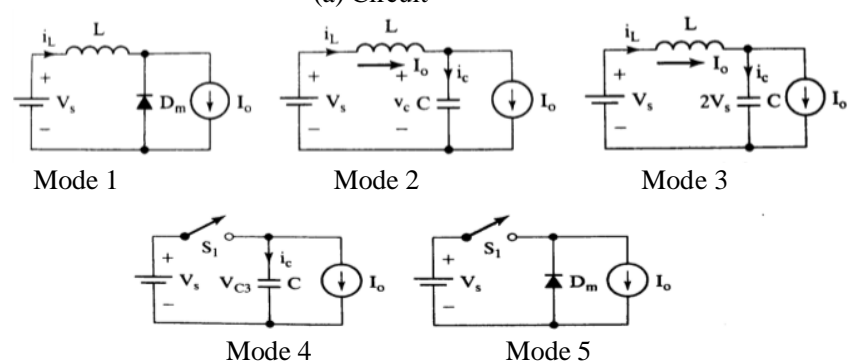

(b) Equivalent circuits

FIG III.2 
Mode 3 - This mode is valid for $0 \leq \mathrm{t} \leq \mathrm{t}_{3}$. The inductor current that falls from 10 to zero is given by

$$
\mathrm{i}_{0}=\mathrm{I}_{0}-\mathrm{I}_{\mathrm{m}} \sin \omega_{0} \mathrm{t}
$$

The capacitor voltage is given by

$$
\mathrm{V}_{\mathrm{c}}=\mathrm{V}_{\mathrm{s}} \cos \omega_{0} \mathrm{t}
$$

This mode ends at $\mathrm{t}=\mathrm{t} 3$ when $\mathrm{il}(\mathrm{t}=\mathrm{t} 3)=0$. And $\mathrm{v}_{\mathrm{c}}(\mathrm{t}=\mathrm{t} 3)$ $=\mathrm{V}_{\mathrm{c} 3}$.

Thus $t_{3}=\sqrt{L C} \sin ^{-1} x$

where $\mathrm{x}=\mathrm{I}_{\mathrm{m}} / \mathrm{I}_{0}==\left(\mathrm{V}_{\mathrm{s}} / \mathrm{I}_{\mathrm{L}} \sqrt{\frac{\mathrm{c}}{\mathrm{L}}}\right)$

Mode 4 - This mode is valid for $0 \leq t \leq t_{4}$. The capacitor supplies the load current 10 and its voltage is given by

$$
\mathrm{V}_{\mathrm{c}}=\mathrm{V}_{\mathrm{c} 3}-\left(\mathrm{I}_{0} / \mathrm{C}\right) \mathrm{t}
$$

This mode ends at $\mathrm{t}=\mathrm{t} 4$ when $\mathrm{Vc}(\mathrm{t}=\mathrm{t} 4)=0$. Thus $\mathrm{t} 4=$ $\mathrm{V}_{\mathrm{c} 3 \mathrm{C} / \mathrm{I}}$

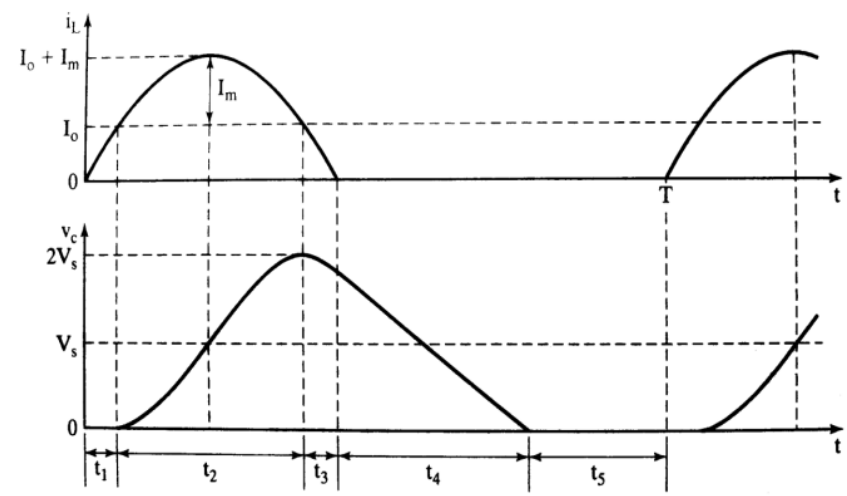

(c) Waveforms

Fig III.3 L Type ZCS Resonant Converter

Mode 5 - This mode is valid for $0 \leq \mathrm{t} \leq \mathrm{t}_{5}$. When the capacitor voltage tends to be negative, the diode $\mathrm{D}_{\mathrm{m}}$ conducts. The load current $\mathrm{I}_{\mathrm{O}}$ flows through diode Dm. This mode ends at time $\mathrm{t}=\mathrm{tS}$ when the switch $\mathrm{S}_{1}$ is turned on again and the cycle is repeated i.e. $\mathrm{t}_{5}=\mathrm{T}-(\mathrm{t} 1+\mathrm{t} 2+\mathrm{t} 3+\mathrm{t} 4)$

\section{ZERO VOLTAGE SWITCHING RESONANTCONVERTERS}

The switches of ZVS resonant converters turn on and off at zero voltage.

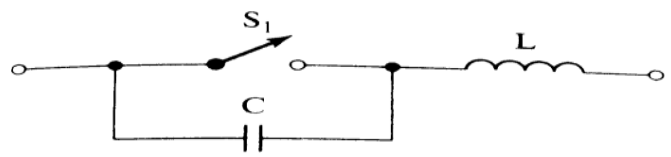

(a) ZVS circuit

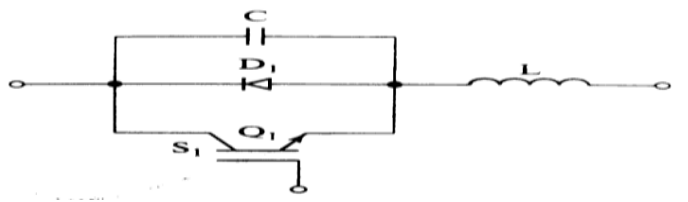

(b) Half-wave

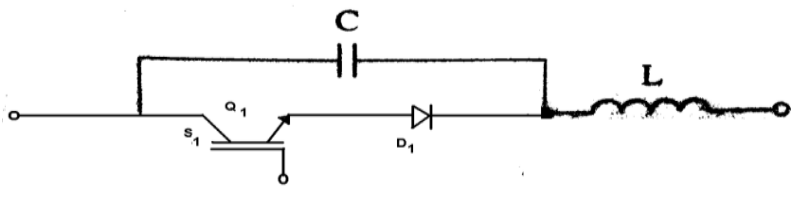

(c) Full-wave

Fig IV.1 Switch Configurations for ZVS Resonant Converters

The capacitor $C$ is connected in parallel with the switch $\mathrm{S}_{1}$ to achieve ZVS. The internal switch capacitance $C_{j}$ is added with the capacitor $\mathrm{C}$ and it affects the resonant frequency only, thereby contributing no power dissipation in the switch. If the switch is implemented with transistor Q1 and an anti-parallel diode D1 as shown, the voltage across $\mathrm{C}$ is clamped by $\mathrm{Dl}$ and the switch is operated in half wave configuration. If the diode $\mathrm{D}_{1}$ is connected in series with Q1 as shown, the voltage across C can oscillate freely and the switch is operated in full wave configuration. A ZVS resonant converter is shown. A ZVS resonant converter is the dual of ZCS resonant converter.

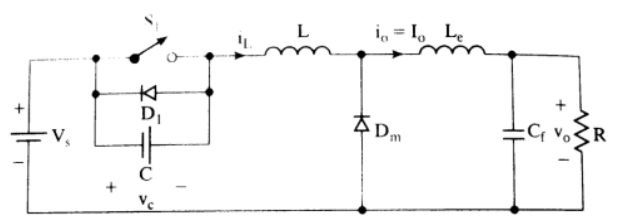

(a) ZVS circuit

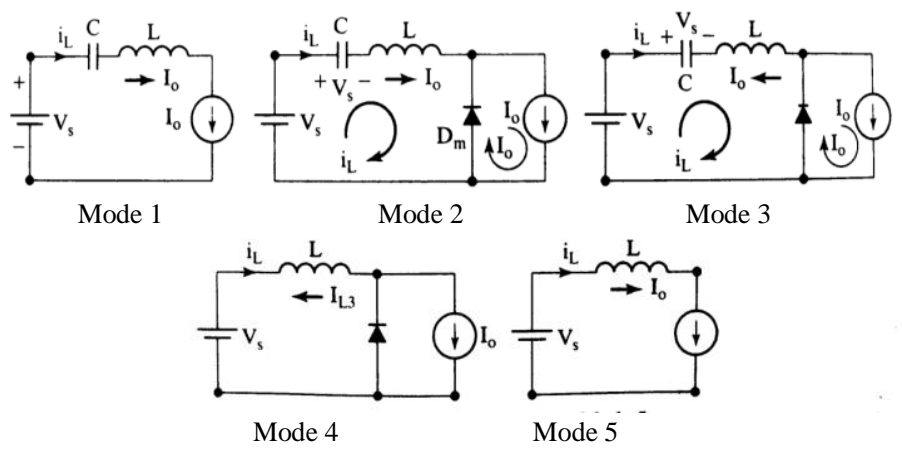

(b) Equivalent circuits

FIG IV.2

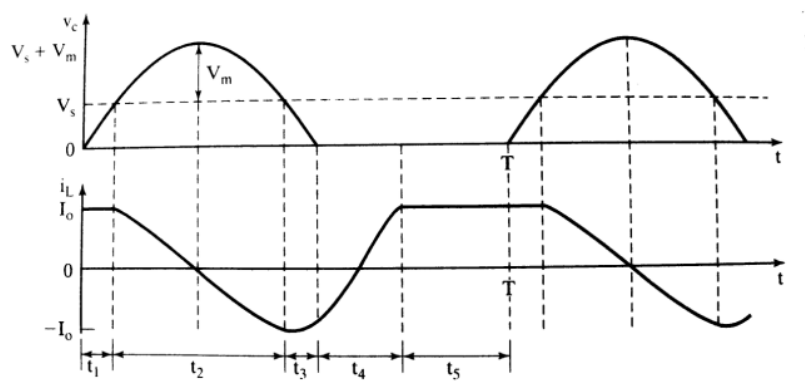

(c) Waveforms

Fig IV.3 ZVS Resonant Converter

The circuit operation can be divide in to 5 modes whose circuits are shown. We shall redefine the time origin, $\mathrm{t}=0$, at the beginning of each mode. 
Mode 1 : This mode is valid for $0 \leq \mathrm{t} \leq \mathrm{t}_{1}$. Both switch $\mathrm{S}_{1}$ and diode $\mathrm{D}_{\mathrm{m}}$ are off. Capacitor $\mathrm{C}$ charges at a constant rate of load

$$
V_{c}=\frac{I_{0}}{C} t
$$

This mode ends at time $\mathrm{t}=\mathrm{t} 1$ when $\mathrm{v}_{\mathrm{C}}(\mathrm{t}=\mathrm{t} 1)=\mathrm{V}_{\mathrm{S}}$. That is $\mathrm{t}_{1}=\mathrm{V}_{\mathrm{S}} \cdot \mathrm{C} / \mathrm{I}_{0}$.

Mode 2: This mode is valid for $0 \leq \mathrm{t} \leq \mathrm{t}_{2}$. The switch $\mathrm{S}_{1}$ is still off, but diode $\mathrm{D}_{\mathrm{m}}$ turns on. The capacitor voltate $\mathrm{v}_{\mathrm{c}}$ is given by

\[ \mathrm{V}_{\mathrm{c}}=\mathrm{V}_{\mathrm{m}} \sin \omega \mathrm{t}+\mathrm{V}_{\mathrm{S}} \]
Where $\mathrm{V}_{\mathrm{m}}=\mathrm{I}_{0} \sqrt{\mathrm{L}_{\mathrm{C}}} \quad$ The peak switch voltage which occurs at $\mathrm{t}=\frac{\pi}{2} \mathrm{LC}$, is

$$
\mathrm{V}_{\mathrm{t}(\mathrm{pk})}=\mathrm{V}_{\mathrm{c}(\mathrm{pk})}=\mathrm{I}_{0} \sqrt{\mathrm{L} / \mathrm{C}}+\mathrm{V}_{\mathrm{s}}
$$

The inductor current $i_{L}$ is given by

$$
\mathrm{I}_{\mathrm{L}}=\mathrm{I}_{0} \cos \omega_{0 \mathrm{t}}
$$

This mode ends at $\mathrm{t}=\mathrm{t}_{2}$ when $\mathrm{v}_{\mathrm{C}}\left(\mathrm{t}=\mathrm{t}_{2}\right)=\mathrm{V}_{\mathrm{S}}$, and

$$
\mathrm{i}_{\mathrm{L}}\left(\mathrm{t}=\mathrm{t}_{2}\right)=-\mathrm{I}_{0} \text {. Therefore, } \mathrm{t}_{2}=\pi \sqrt{\mathrm{LC}}
$$

Mode 3 : This mode is valid for $0 \leq \mathrm{t} \leq \mathrm{t}_{3}$. The capacitor voltage that falls from $v_{S}$ to zero is given by

$$
\mathrm{V}_{\mathrm{c}}=\mathrm{V}_{\mathrm{s}}-\mathrm{V}_{\mathrm{m}} \sin \omega_{0 \mathrm{t}}
$$

The inductor current $i$ is given by

$$
\mathrm{iL}=-\mathrm{I}_{0} \cos \omega_{0 \mathrm{t}}
$$

This mode ends at $\mathrm{t}=\mathrm{t} 3$ when $\mathrm{v}_{\mathrm{c}}(\mathrm{t}=\mathrm{t} 3)=0$, and

iL $(t=t 3)=$ iL3 Thus, $t_{3}=\sqrt{L C} \sin ^{-1} x$

Where, $\mathrm{x}=\mathrm{V}_{\mathrm{s}} \mathrm{V}_{\mathrm{m}}=\left(\mathrm{V}_{\mathrm{s}} / \mathrm{I}_{0}\right) \sqrt{\mathrm{C} / \mathrm{L}}$

Mode 4 : This mode is valid for $0 \leq t \leq t_{4}$. Switch $S_{1}$ is turned on and diode $\mathrm{D}_{\mathrm{m}}$ remains on. The inductor current which rises linearly from $\mathrm{I}_{13}$ to $\mathrm{I}_{0}$ is given by

$$
\mathrm{i}_{\mathrm{L}}=\mathrm{IL}_{\mathrm{L}}+\left(\mathrm{V}_{\mathrm{S}} / \mathrm{L}\right) \mathrm{t}
$$

This mode ends at time $\mathrm{t}=\mathrm{t} 4$ when $\mathrm{iL}_{\mathrm{L}}(\mathrm{t}=\mathrm{t} 4)=\mathrm{I}_{0}$. Thus $\mathrm{t} 4=\left(\mathrm{I}_{0}+\mathrm{IL}_{\mathrm{L}}\right)\left(\mathrm{L} / \mathrm{V}_{\mathrm{S}}\right)$. I13 has a negative value.

Mode 5 : This mode is valid for $0 \leq t \leq t_{5}$. Switch $S_{1}$ is on but $\mathrm{D}_{\mathrm{m}}$ is off. The load current $\mathrm{I}_{0}$ flows through the switch. This mode ends at time $t=t_{5}$, when the switch $S_{1}$ is turned off again and the cycle is repeated. That is $\mathrm{t}_{5}=\mathrm{T}-$ $\left(\mathrm{t} 1+\mathrm{t}_{2}+\mathrm{t}_{3}+\mathrm{t} 4\right)$.

The waveforms for il and $v_{c}$ are shown. The equation

$$
\mathrm{V}_{\mathrm{t}(\mathrm{pk})}=\mathrm{V}_{\mathrm{c}(\mathrm{pk})}=\mathrm{I}_{0} \sqrt{\mathrm{L} / \mathrm{C}}+\mathrm{V}_{\mathrm{s}}
$$

shows that the peak switch voltage $\mathrm{V}_{\mathrm{t}}(\mathrm{pk})$ is dependent on the load current I0. Therefore a wide variation in the load current results in a wide variation of the switch voltage.
For this reason, ZVS converters are used only for constantload applications. The switch must be turned on only at zero voltage. Otherwise, the energy stored in $\mathrm{C}$ can be dissipated in the switch. To avoid this situation, the antiparallel diode $\mathrm{D}_{1}$ must conduct before turning on the switch.

\section{V.COMPARISION OF ZCS AND ZVS CONVERTERS}

ZCS can eliminate switching losses at turnoff and reduce the switching losses at turnon. Because a relatively large capacitor is connected across the diode $\mathrm{D}_{\mathrm{m}}$ the inverter operation becomes insensitive to the diode $\mathrm{s}$ junction capacitance When power MOSFETs are used for ZCS the energy stored in the device s capacitance is dissipated during turn on This capacitive turn on loss is proportional to the switching frequency.

During turn on a high rate of change of voltage may appear in the gate drive circuit due to the coupling through the Miller capacitor, thus increasing switching loss and noise. Another limitation is that the switches are under high current stress, resulting in higher conduction loss.

\section{V.1. ZERO VOLTAGE SWITCHING TECHNIQUE}

Voltage-Mode Resonant Switches A resonant switch represents a sub-circuit consisting of semiconductor switch SI and auxiliary resonant elements L, and C,. For a currentmode resonant switch, as shown in Fig. 1(a), inductor L, is in series with switch SI to achieve zero-current switching; in a voltage-mode resonant switch, as

shown in Fig. 1(b), capacitor C, is in parallel with switch SI to achieve zero-voltage switching.

As in the case of a current-mode resonant switch, the structure of SI determines the operation mode of the voltage- mode resonant switch. If the ideal switch SI is implemented by a transistor $\mathrm{Q}$, and an anti-parallel diode, $\mathrm{D}$, , as shown in Fig. 2(b), the voltage across capacitor $\mathrm{C}$, is clamped by DI to a minimum value, and the resonant switch is operating in a half-wave mode. On the other hand, if SI is implemented by $\mathrm{Q}$, in series with $\mathrm{D}$, , as shown in Fig. 2(c), and the voltage on $\mathrm{C}$, can oscillate freely, then the resonant switch is operating in a full-wave mode.

Notice that in a current-mode resonant switch, the resonant interaction between $\mathrm{L}$, and $\mathrm{C}$, is initiated by the turn-on of SI, while on a voltage-mode resonant switch, it is initiated by the turn-off of S1.

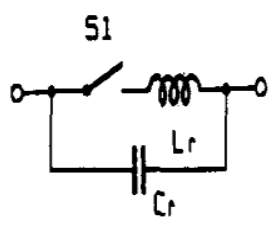

(a)

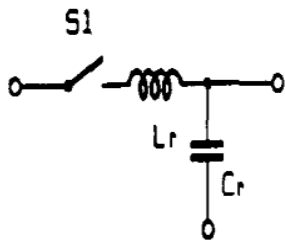



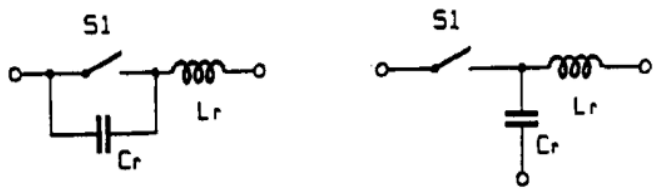

(b)

Fig V.1. (a) Current mode resonant switches. (b) Voltage mode resonant switches

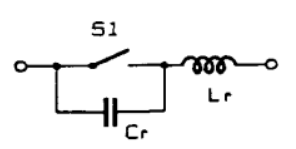

(a)
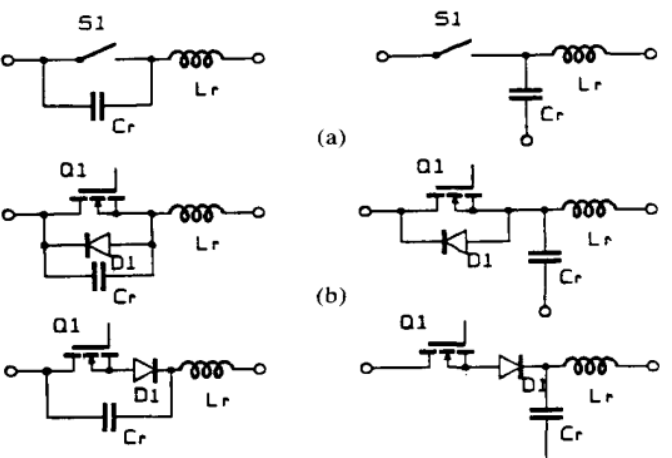

(b)

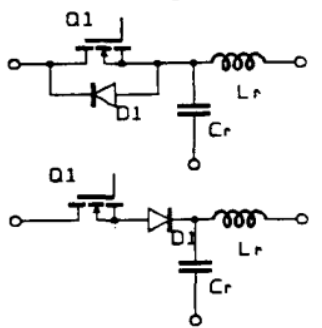

(c)

Fig V.2 Voltage mode resonant switches. (a) General notation. (b) Half wave mode implementation. (c) Full wave mode implementation

\section{CIRCUIT DESCRIPTION AND OPERATING PRINCIPLES}

\section{A. Circuit Description}

The aim of this work is to construct a high-efficiency power electronic converter that can be implemented in the renewable energy generation systems. This application of a power electronic converter depends on the effectiveness of its structure in minimizing switching losses in the energy transformation interval. Soft switching has potential to provide lossless switch-ing and has become increasingly popular with researchers. This work develops a novel current-fed resonant converter with ZVS and ZCS operations of both the active power switch and the rectifying diode for energy

conversion. Fig. 1 shows a basic circuit diagram of the proposed novel single-switch resonant converter for renewable energy generation applications. It comprises a choke inductor $\mathrm{L}_{\mathrm{m}}$, a metal-oxide-semiconductor fieldeffect transistor (MOSFET) that operates as a power switch $\mathrm{S}$, a shunt capacitor $\mathrm{C}$, a resonant inductor $\mathrm{L}_{\mathrm{s}}$, an energyblocking diode $\mathrm{D}$, and a filter capacitor $\mathrm{C}_{\mathrm{o}}$. The capacitor $\mathrm{C}_{\mathrm{o}}$ and the load resistance $\mathrm{R}$ together form a first-order low-pass output filter, which reduces the ripple voltage below a specified level. The MOSFET is a favoured device because its body diode can be used as an antiparallel diode $\mathrm{D}_{\mathrm{E}}$ for a bidirectional power switch.

\section{B. Circuit Operating Principles}

The novel single-switch resonant power converter for renewable energy generation applications is analysed using the following assumptions.

1. The switching elements of the converter are ideal, such that the drop in forward voltage across the resistance of the power switch in the $\mathrm{ON}$ state is negligible.

2. The equivalent series resistance of the capacitance and stray capacitances is negligible.

3. The characteristics of the passive components are linear, time invariant, and independent of frequency.

4. The filter capacitance $\mathrm{C}_{\mathrm{o}}$ at the output terminal is typically very large; the output voltage across capacitor $\mathrm{C}_{\mathrm{o}}$ can therefore be treated as an ideal $\mathrm{dc}$ voltage in each switching cycle.

The choke inductance $\mathrm{L}_{\mathrm{m}}$ at the input terminal of the novel single-switch resonant power converter is large. Therefore, the input current through the inductor $\mathrm{L}_{\mathrm{m}}$ can be treated as an idealized dc current in each switching cycle.

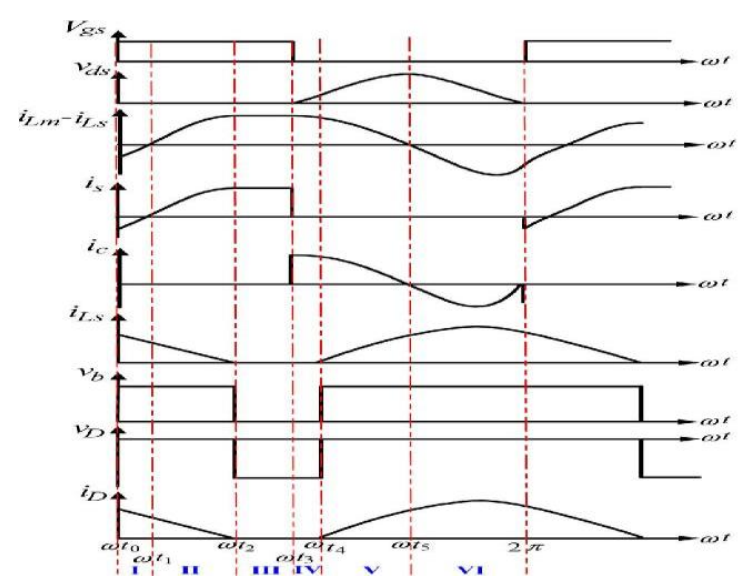

Fig.2. Steady-state operating waveforms of the novel singleswitch resonant power converter.

The key waveforms for each mode of the proposed converter are shown in Fig. 2. One switching cycle is divided into six modes, which are described as follows.

Mode $\mathrm{I}-$ Between $\omega \mathrm{t}_{0}$ and $\omega \mathrm{t}_{1}$ : Prior to Mode $\mathrm{I}$, the active power switch $\mathrm{S}$ is off. The resonant tank current $\mathrm{i}_{\mathrm{LS}}$ is positive and exceeds the dc input current $i_{\text {Lm }}$. The power switch must be turned on only at zero voltage. Otherwise, the energy stored in the capacitor $\mathrm{C}$ will be dissipated in the active power switch $\mathrm{S}$. To prevent this situation, the antiparallel diode $\mathrm{D}_{\mathrm{E}}$ must conduct before the power switch is turned on. Since the capacitor current $i_{C}$ is negative, it flows through capacitor $C$. When the capacitor voltage $v_{C}$ falls to zero, a turn-on signal is applied to the gate of the active power switch $S$. Therefore, the active power switch $S$ turns on under ZCS and ZVS conditions .

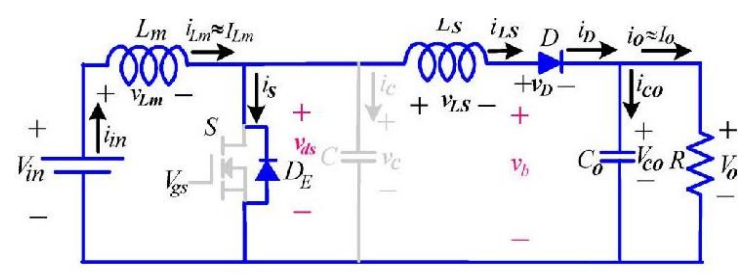

Fig. 3. Equivalent circuit of Mode I 


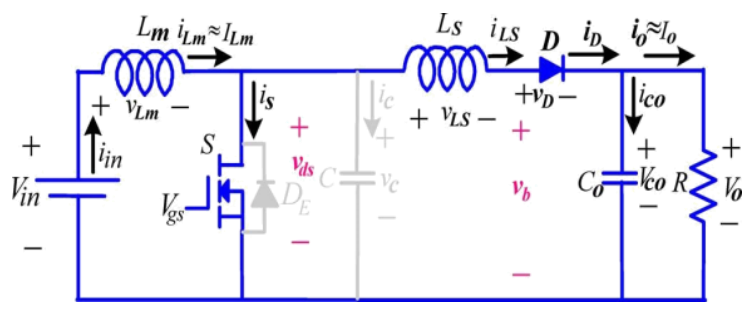

Fig. 4. Equivalent circuit of Mode II

At the beginning of this mode, the antiparallel diode $D_{E}$ conducts because the difference between currents $i_{L m}-$ $\mathrm{i}_{\mathrm{Ls}}$ is negative. In this mode, the energy-blocking diode $\mathrm{D}$ is turned on because the resonant tank current $i_{L s}$ is positive. Fig. 3 presents the equivalent circuit of this mode. The initial condition of the inductor current $\mathrm{i}_{\mathrm{Ls}}$ is $\mathrm{I}_{\mathrm{Ls}}{ }^{+}$.

Then, the instantaneous inductor current and the voltage across capacitor $\mathrm{C}$ can be evaluated using

$i_{L s}(t)=-\frac{I_{0} R}{L}\left(t-t_{0}\right)+I_{L s 0}^{+}$

$$
\mathrm{V}_{\mathrm{C}}(\mathrm{t})=0
$$

This mode ends as soon as the antiparallel diode $D_{E}$ is reverse biased by a positive current $i_{L m}-i_{L s}$.

Mode II-Between $\omega \mathrm{t}_{1}$ and $\omega_{2}$ : In this period, the switch $\mathrm{S}$ remains in the ON state. Fig. 4 shows the equivalent circuit. The line voltage is applied to the choke inductor $L_{m}$, and $i_{L m}$ increases continuously. In this mode, the current $\mathrm{i}_{\mathrm{L}}-\mathrm{i}_{\mathrm{Ls}}$ naturally commutates from the antiparallel diode $D_{E}$ to the active power switch S. Accordingly, the voltage across the capacitor $\mathrm{C}$ is clamped at zero. The resonant current $\mathrm{i}_{\mathrm{Ls}}$ passes through the energy-blocking diode D. During this interval, the inductor current $\mathrm{i}_{\mathrm{Ls}}$ is expressed as follows, where $\mathrm{I}_{\mathrm{Ls}}{ }_{1}^{+}$is the initial current in the inductor $\mathrm{i}_{\mathrm{Ls}}$ :

$\mathrm{i}_{\mathrm{L} s}(\mathrm{t})=-\frac{\mathrm{I}_{0} \mathrm{R}}{\mathrm{L}}\left(\mathrm{t}-\mathrm{t}_{0}\right)+\mathrm{I}_{\mathrm{Ls} 1}^{+}$

$I_{L s 1}^{+}(t)=-\frac{I_{0} R}{L}\left(t_{1}-t_{0}\right)+I_{L s 0}^{+}$

The following equation gives the voltage $v_{c}(t)$ across the resonant capacitor $\mathrm{C}$ :

$$
\mathrm{V}_{\mathrm{C}}(\mathrm{t})=0
$$

The circuit operation enters Mode III when the inductor current $i_{L s}$ falls to zero.

Mode III-Between $\omega t_{2}$ and $\omega t_{3}$ : In Mode III, the active power switch $S$ remains in the $O N$ state, and the input dc current $i_{L m}$ continuously increases. The choke inductor current $i_{L m}$ flows through the active power switch $S$. prevented from going negative by the energy - blocking diode $D$. Notably, the de input source is never connected directly to the output lad in the novel single - switch converter. Energy is stored in the choke inductor $L_{m}$ when the active power switch is turned on and is transferred to the output load when the active power switch is turned off

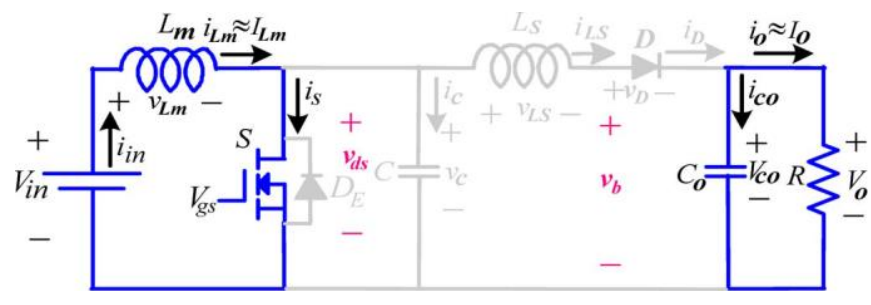

Fig. 5. Equivalent circuit of Mode III.

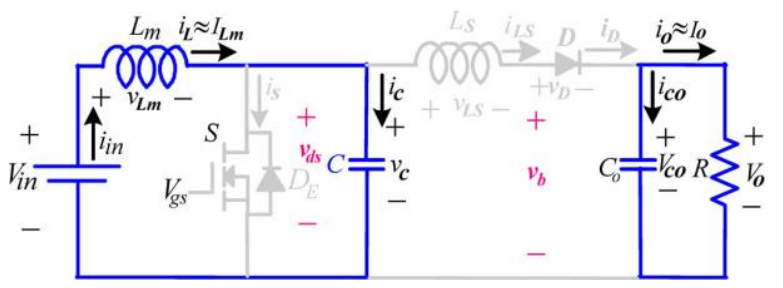

Fig.6. Equivalent circuit of Mode IV

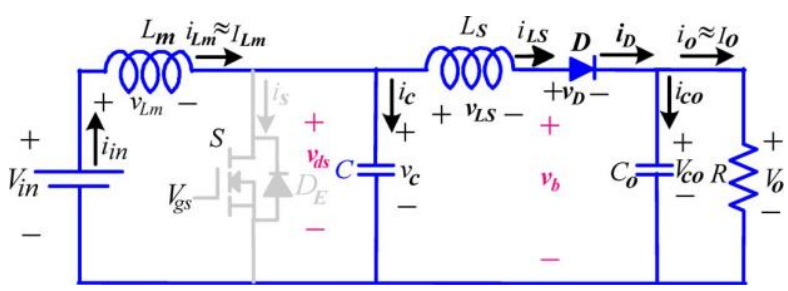

Fig.7. Equivalent circuit of Mode V

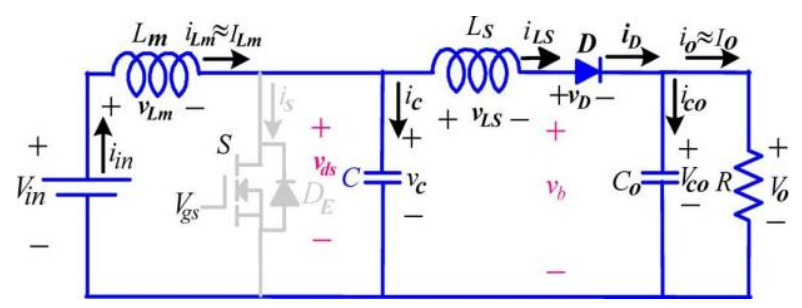

Fig. 8. Equivalent circuit of Mode VI.

The following equation yields the capacitor voltage $v_{c}(t)$ of the resonant capacitor:

$$
\begin{aligned}
\mathrm{v}_{\mathrm{c}}(\mathrm{t})= & \mathrm{Z}_{\mathrm{o}} \mathrm{I}_{\mathrm{Lm}} \sin \omega_{\mathrm{o}}\left(\mathrm{t}-\mathrm{t}_{5}\right)+\mathrm{V}_{\mathrm{C}}{ }_{6}^{+} \cos \omega_{\mathrm{o}}\left(\mathrm{t}-\mathrm{t}_{5}\right)+\mathrm{I}_{\mathrm{o}} \mathrm{R} \\
& {\left[1-\cos \omega_{\mathrm{o}}\left(\mathrm{t}-\mathrm{t}_{5}\right)\right]+\mathrm{I}_{\mathrm{C}}{ }^{+} \cdot \mathrm{Z}_{\mathrm{o}} \sin \omega_{\mathrm{o}}\left(\mathrm{t}-\mathrm{t}_{5}\right) }
\end{aligned}
$$

Before the cycle of the resonant inductor current $i_{L s}$ oscillation ends, the active power switch $S$ is kept off condition, constraining the positive current to flow continuously through the energy-blocking diode D.

The inductor current $i_{L s}$ falls until it reaches zero and is 


\section{VII.OPERATING CHARACTERISTICS}

To simplify the description of the operating characteristics of this novel single-switch resonant power converter, it is generally assumed that, when the low-pass filter or load circuit is a voltage sink type, the output capacitance in parallel with the load resistor is assumed to be very large, so its voltage is approximately constant. Therefore, the output circuit viewed from the output terminals of the rectifier can be replaced by a constant voltage sink. As a result, the link voltage has constant positive and negative amplitudes, depending on whether the inductor current enters or leaves the energy-blocking diode, respectively.

As shown in Fig. 1, the novel single-switch resonant power converter consists of a choke inductor $\mathrm{L}_{\mathrm{m}}$, which generates a ripple-free constant current source, a MOSFET

that is antiparallel with a body diode $D_{E}$, a resonant capacitor $\mathrm{C}$ that is connected in parallel with the body diode, a resonant inductor $\mathrm{L}_{\mathrm{s}}$, an energy-blocking diode $\mathrm{D}$ that is connected in series with the parallel combination of the body diode and the capacitor, and a first-order low-pass output filter $\mathrm{C}_{\mathrm{o}}-\mathrm{R}$.

Fig. 2 displays the idealized steady-state voltage and current waveforms of the proposed novel single-switch resonant power converter for a switching frequency $f_{s}$ and a resonant frequency $f_{0}$. Notably, operating below resonance is preferred because the active power switch turns on at zero current and zero voltage; thus, the freewheeling diode does not need to have very fast reverse-recovery characteristics. In the positive cycle of the current through the inductor $\mathrm{L}_{\mathrm{s}}$, the power is supplied to the load resistor $\mathrm{R}$ through the energy-blocking diode $\mathrm{D}$.

To realize ZVS operation of the active power switch, the turn-on signal of the active power switch $\mathrm{S}$ should be applied while its body diode is conducting. Owing to the discontinuous interval in Fig. 3, one operating cycle of the switching frequency $\mathrm{f}_{\mathrm{s}}$ exceeds $360^{\circ}$ at the resonant frequency $f_{o}$, and therefore, in this mode of operation,

$\mathrm{f}_{\mathrm{s}}<\mathrm{f}_{\mathrm{o}}$. Accordingly, the relationships between switching frequency $f_{s}$ and resonant frequency $f_{o}$ must satisfy the following equation:

$$
\mathrm{f}_{\mathrm{s}} \leq \mathrm{f}_{\mathrm{o}}=\frac{1}{2 \pi \sqrt{\mathrm{L}_{\mathrm{s}} \mathrm{C}}}
$$

During the time that the inductor current $\mathrm{i}_{\mathrm{Ls}}$ is positive, the power is fed to the load through the energy-blocking diode D. When the energy-blocking diode $\mathrm{D}$ is turned on, the resonant circuit must be under damped to achieve resonant operation. That is,

$$
\mathrm{R} \leq 2 \sqrt{\frac{\mathrm{L}_{\mathrm{S}}}{\mathrm{C}}}
$$

The following equation gives the efficiency of the proposed novel single-switch resonant power converter:

$$
\eta=\frac{V_{o} \cdot I_{o}}{V_{\text {in }} \cdot I_{\text {in }}}
$$

\section{VIII.EXPERIMENTAL RESULTS}

A novel single-switch resonant power converter is designed and used in a renewable energy generation system as an example to demonstrate the relevant theory. The input of the proposed novel single-switch resonant power converter was connected to a small-scaled solar energy generation system that consisted of a dc source with an output voltage of $15 \mathrm{~V}$. A prototype of the novel single-switch resonant power converter topology was established in a laboratory to verify its functionality. The conduction losses of the novel singleswitch resonant power converter are proportional to the forward volt-age of the energy-blocking diode. The losses can be reduced by applying Schottky diodes. To realize ZVS operation of the active power switch and ZCS operation of the energy-blocking diode of this novel converter, the switching frequency must satisfy $f_{s}<f_{o}$. The developed novel single-switch resonant power converter is applied to a $10-\Omega$ load resistor.

An experiment was performed under the following conditions: Switching frequency $\mathrm{f}_{\mathrm{s}}=70 \mathrm{kHz}$, resonant frequency $\mathrm{f}_{\mathrm{o}}=86 \mathrm{kHz}$, duty cycle $\mathrm{k}=0.357$, output voltage $\mathrm{V}_{\mathrm{o}}=18.0 \mathrm{~V}$, and output power $\mathrm{P}_{\mathrm{o}}=32.4 \mathrm{~W}$. To reduce the input current ripple and maintain the stability of the output voltage, the low-pass filters at the input and output terminals, which use a choke inductor and an electrolytic capacitor, are set to $\mathrm{L}_{\mathrm{m}}=8 \mathrm{mH}$ and $\mathrm{C}_{\mathrm{o}}=220 \mu \mathrm{F}$, respectively.

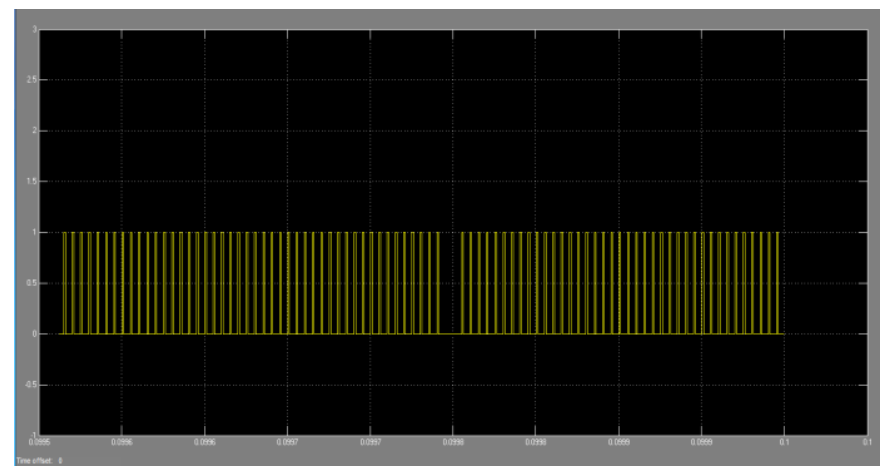

Fig. 9. Trigger signal waveforms of the active power switch

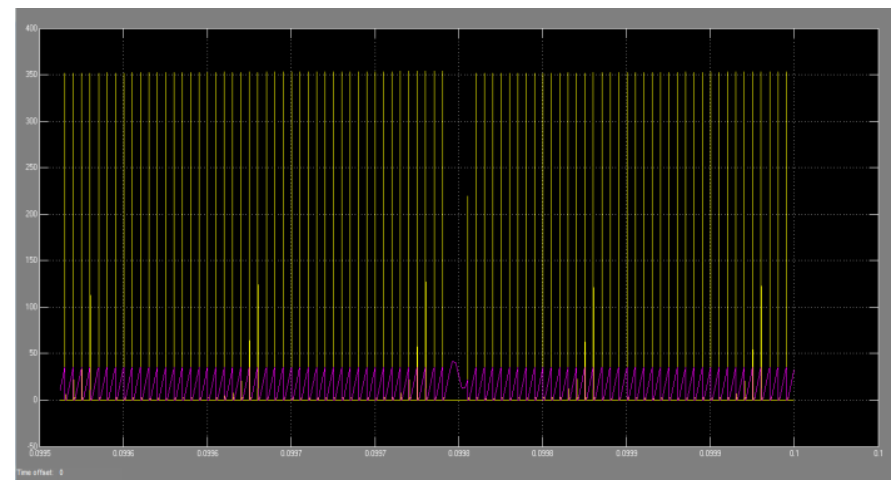

Fig. 10. Voltage and current waveforms of the active power switch. 
The low-pass filter is designed to be small, light, and low cost. Under the aforementioned operating conditions, the two parameters of the novel single-switch resonant power converter are calculated as follows:

$$
\begin{aligned}
& \mathrm{C}=0.18 \mu \mathrm{F} \\
& \mathrm{L}_{\mathrm{s}}=19 \mu \mathrm{H} .
\end{aligned}
$$

The following experimental results were measured at input voltage $\mathrm{v}_{\text {in }}=15 \mathrm{~V}$ and input current $\mathrm{i}_{\text {in }}=2.22 \mathrm{~A}$. Fig. 9 shows the waveforms of the active power switch $\mathrm{S}$, where $\mathrm{v}_{\mathrm{GS}}$ represents the trigger signal on active power switch $\mathrm{S}$ and $v_{\text {DS }}$ represents the voltage across the active power switch S. Fig. 10 depicts the voltage and current waveforms of the active power switch S. Evidently, the active power switch is operated with ZVS. Fig. 11 displays the voltage and current waveforms of the choke inductance $\mathrm{L}_{\mathrm{m}}$ at the input terminal. The choke inductance $\mathrm{L}_{\mathrm{m}}$ is sufficiently large that the input current $i_{\text {Lm }}$ is almost constant. Fig. 12 sketches the voltage waveform $\mathrm{v}_{\mathrm{C}}$ and the current waveform $\mathrm{i}_{\mathrm{C}}$ of the resonant capacitor, respectively. Fig. 13 plots the voltage waveforms of the resonant inductor $\mathrm{v}_{\mathrm{Ls}}$ and the current waveforms of the resonant inductor $i_{\text {Ls }}$. Fig. 14 illustrates the voltage and current waveforms of the energy blocking diode.
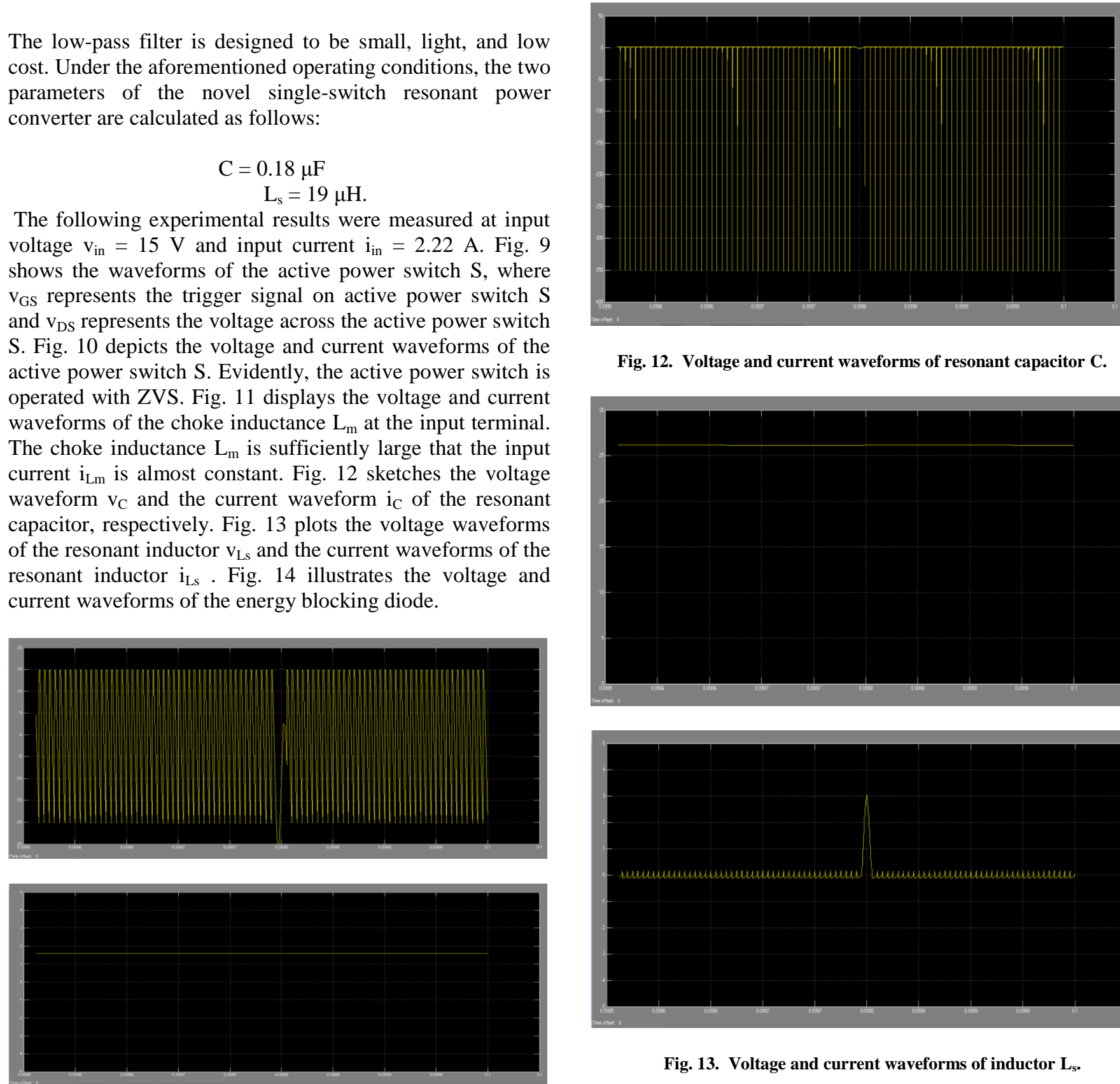

Fig. 12. Voltage and current waveforms of resonant capacitor $C$.
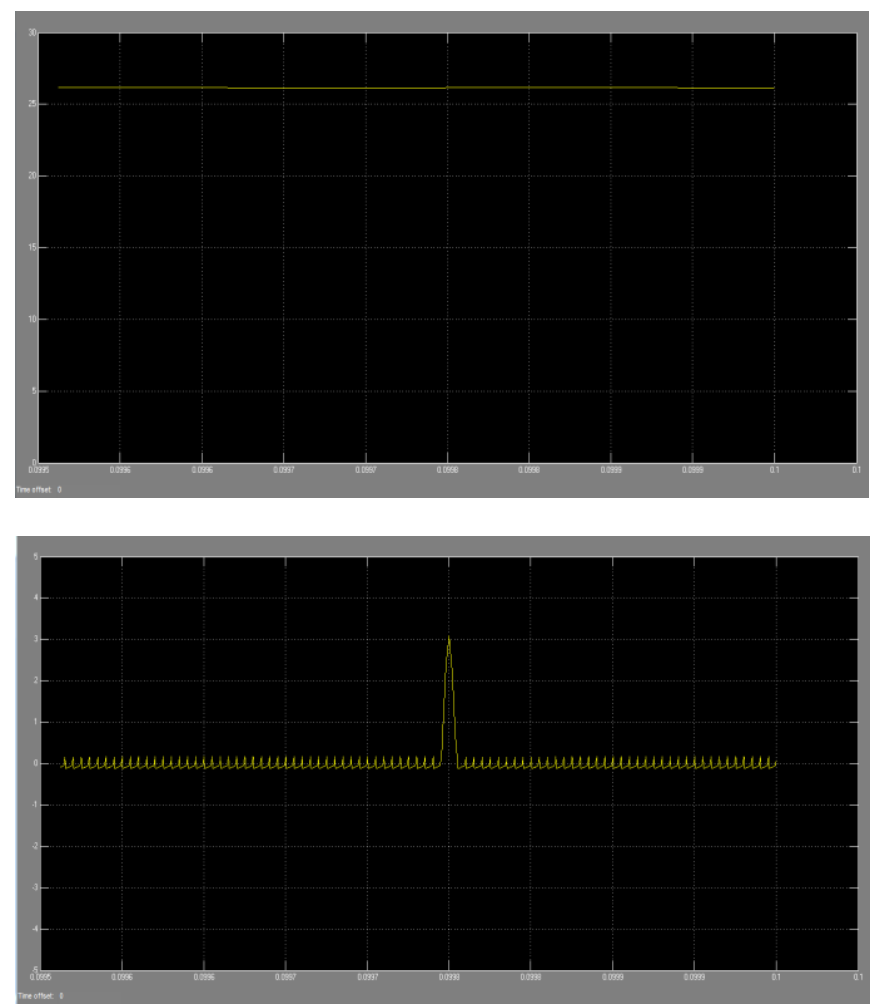

Fig. 13. Voltage and current waveforms of inductor $L_{s}$.

Fig. 11. Voltage and current waveforms of the choke inductor.
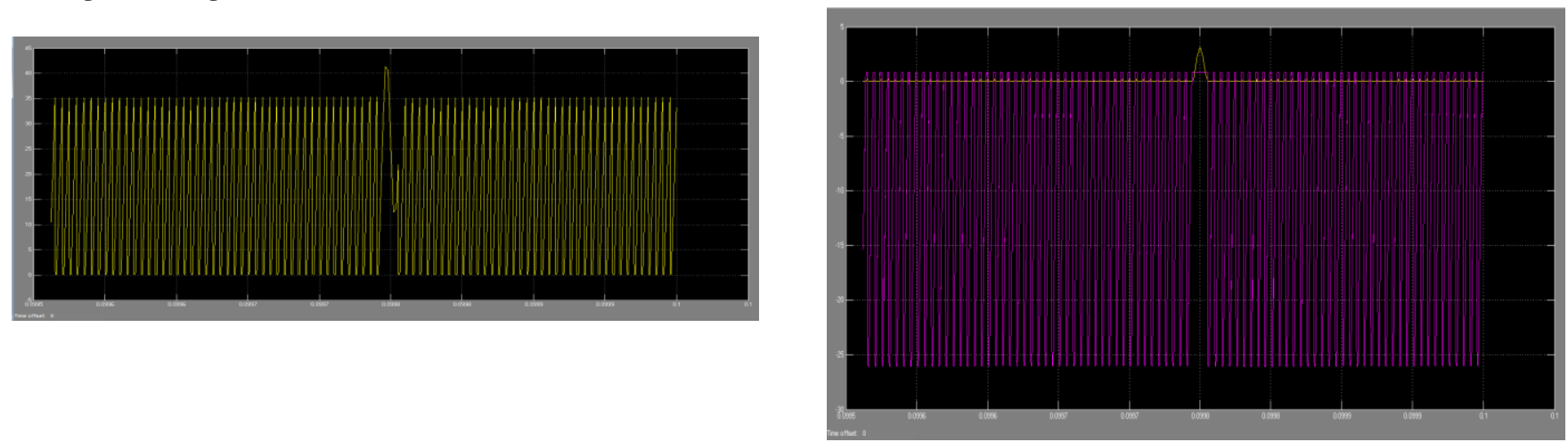

Fig. 14. Voltage and current waveforms of the energy-blocking diode 

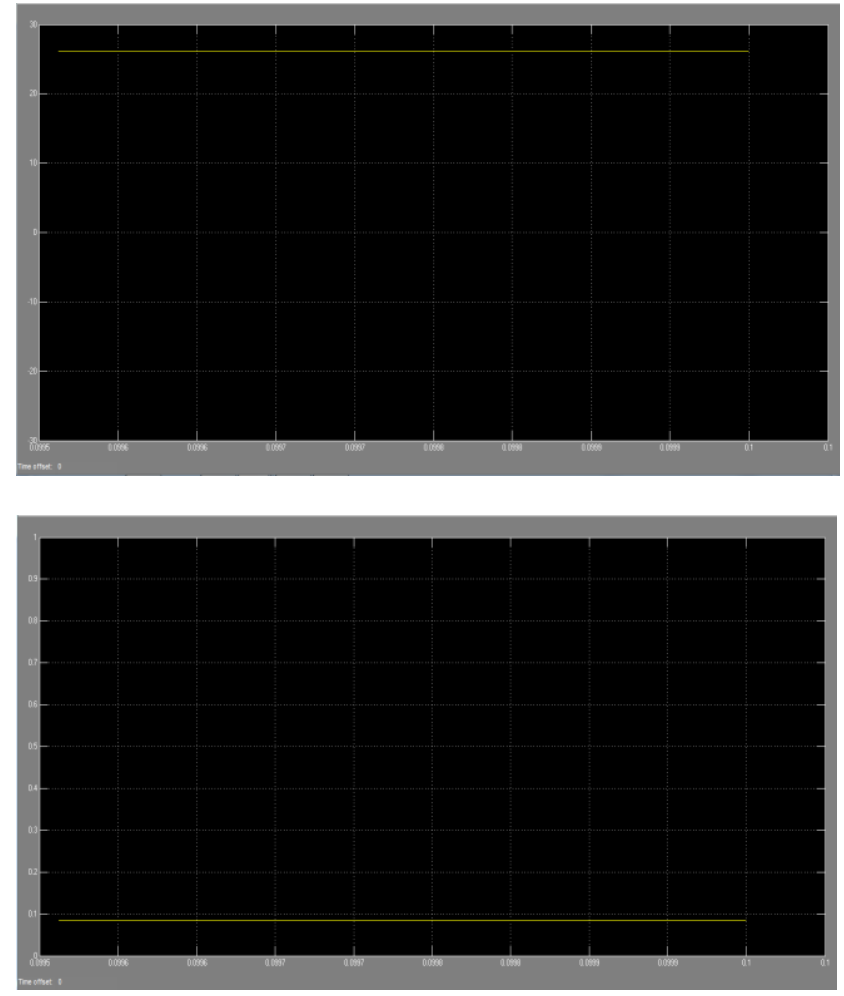

Fig. 15. Load voltage and current waveforms.

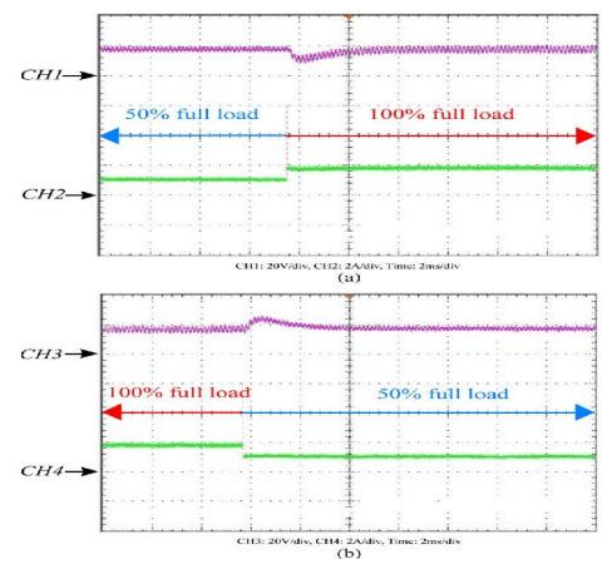

Fig. 16. Measured results from the novel single-switch resonant power converter of the step load changes between $50 \%$ and $100 \%$ of the full power.

(a) Output voltage and current responses to step changes of the loads between $50 \%$ and $100 \%$ of the full load. (b) Output voltage and current responses to step changes of the loads between $100 \%$ and $50 \%$ of the full load.

This figure Reveals that this diode is operating under the ZCS condition, which can reduce the switching loss and increase the energy conversion efficiency. Fig. 17 gives the output voltage and current waveforms of the load, which are smooth dc voltage and current waveforms, respectively.

The output voltage equals $18 \mathrm{~V}$, which can be used to drive light-emitting diode lighting systems. The energy conversion efficiency of the proposed novel single-switch resonant power converter is as high as $97.3 \%$ at output power $\mathrm{P}_{\mathrm{o}}=$ $32.4 \mathrm{~W}$. In addition, the pro-posed novel single-switch resonant power converter has great potential for use in renewable energy generation applications. Fig. 18 illustrates the transient response of the step load changes between $50 \%$ and $100 \%$ of the full power. It can be observed from the waveforms that the output voltage and current can follow the change

\section{CONCLUSION}

In this project, a novel single-switch resonant power converter with an energy-blocking diode has been designed for use in a solar energy generation system. The structure of the proposed converter is simpler and cheaper than other resonant power converters, which require numerous components. The novel resonant converter is analyzed, and performance characteristics are presented. The developed novel single-switch resonant power converter offers the advantages of soft switching, reduced switching losses, and increased energy conversion efficiency. The output power can be determined from the characteristic impedance of the resonant tank by adjusting the switching frequency of the converter. The novel single-switch resonant power converter is supplied by a solar energy generation system to yield the required output conditions. The experimental results reveal the effectiveness of the developed novel single-switch resonant power converter in solar energy generation. When the high-frequency novel single-switch resonant power converter is applied to a resistive load, the satisfactory energy conversion efficiency is $97.3 \%$. The novel singleswitch resonant power converter topology yields a higher energy conversion efficiency than conventional class-D resonant converters. Favorable performance is obtained at lower cost with fewer circuit components.

\section{REFERENCES}

[1] J. Parikh and K. Parikh, "Growing pains: Meeting India's energy needs in the face of limited fossil fuels," IEEE Power Energy Mag., vol. 10, no. 3, pp. 59-66, May 2012.

[2] J. I. Nishizawa, "A method to avoid dangers caused by fossil fuels,” Proc. IEEE, vol. 96, no. 10, pp. 1559-1561, Oct. 2008.

[3] P. Thounthong, B. Davat, S. Rael, and P. Sethakul, "Fuel cell high-power applications," IEEE Ind. Electron. Mag., vol. 3, no. 1, pp. 32-46, Mar. 2009.

[4] W. Wongsaichua, W. J. Lee, S. Oraintara, C. Kwan, and F. Zhang, "In-tegrated high-speed intelligent utility tie unit for disbursed/renewable generation facilities," IEEE Trans. Ind. Appl., vol. 41, no. 2, pp. 507-513, Mar./Apr. 2005.

[5] Z. Liang, R. Guo, J. Li, and A. Q. Huang, "A high-efficiency PV module-integrated DC/DC converter for PV energy harvest in FREEDM systems," IEEE Trans. Power Electron., vol. 26, no. 3, pp. 897-909, Mar. 2011. 